\title{
Close proximity detection interference with acoustic telemetry: the importance of considering tag power output in low ambient noise environments
}

Steven Thomas Kessel ${ }^{* *}$, Nigel Edward Hussey', Dale Mitchell Webber², Samuel Harvey Gruber ${ }^{3}$, Joy Michelle Young ${ }^{4}$, Malcolm John Smale, ${ }^{5,6}$ and Aaron Thomas Fisk ${ }^{1}$

\begin{abstract}
Background: When employing acoustic telemetry to study aquatic species, understanding the functional dynamics of the monitoring system is essential for effective study design, data interpretation, and analysis. Typically, researchers are concerned with maximum effective detection range and consequently tend to employ the largest most powerful tags the study species can carry without considerable energetic burden. In ideal acoustic conditions of low ambient noise environments, low attenuation, and reflective structure, higher powered tags can be detected at larger distances from the receiver, but they can also be subject to the phenomenon 'Close Proximity Detection Interference' (CPDI). This occurs when reflective barriers, such as a calm water surface and/or hard substrate, result in strong transmission echoes that interfere with the transmission sequence. As a result, transmissions in close proximity to the receiver are not effectively decoded and logged.
\end{abstract}

Results: CPDI was assessed from the results of three detection range tests conducted using the Vemco $69 \mathrm{kHz}$ telemetry system in three contrasting study systems: a sheltered marine Arctic embayment, a temperate freshwater lake, and an exposed marine sub-tropical reef line. For the Arctic embayment, CPDI was absent with the lower power V9 tag ( $90 \%$ of transmissions received at $55 \mathrm{~m}$ ) but was recorded for the $\mathrm{V} 13$ tag and was most prevalent for the highest power V16 tag (18\% and 8\% of transmissions received at $55 \mathrm{~m}$, respectively). Comparing V16 tag detection profiles between study systems, CPDI was evident in the low ambient noise Arctic embayment and temperate freshwater lake (highest transmission proportions recorded at 370 and $207 \mathrm{~m}$, respectively) but was absent on the high ambient noise sub-tropical reef line. Functional examples highlight the ways in which CPDI can affect different study designs if not acknowledged or accounted for.

Conclusions: CPDI was shown to be the most prominent in low ambient noise study systems and should be considered when choosing tag type/power during study design. If unaccounted for, CPDI could lead to misinterpretation during the analysis of acoustic telemetry data. The identification of CPDI highlights the complexities associated with the functionality of acoustic telemetry systems and supports recommendations for thorough detection range testing.

Keywords: Acoustic telemetry, Detection probability, Detection range test, CPDI, Doughnut effect

\footnotetext{
* Correspondence: skessel@uwindsor.ca

${ }^{1}$ Great Lakes Institute for Environmental Research, University of Windsor, 401

Sunset Ave, Windsor, ON N9B 3P4, Canada

Full list of author information is available at the end of the article
} 


\section{Background}

Due to its ease of use and adaptable application, acoustic telemetry has been increasingly used in a wide range of aquatic environments/water body types and climatic conditions, with globally distributed studies focused on a highly diverse range of species and taxa [1]. This adaptable application has also led to acoustic telemetry being adopted as a tool to investigate a wide range of scientific questions, including investigations into migration, home range/activity space, influence of environmental drivers, habitat use and/or selection, MPA effectiveness, ecological roles, and diel/circadian patterns (reviewed in [1]). For any study employing acoustic telemetry, it is essential to understand the technical aspects of equipment and how these influence the study design and consequently the results [1-4].

In response to the growing demand for accessible acoustic telemetry equipment, several manufacturers have developed systems, with the two most common types either simply recording the presence/absence of individuals or providing specific positional data [1]. Typically, these systems employ battery-powered acoustic tags that are attached/surgically implanted into target animals and autonomous receivers that are fixed in strategic positions to detect the tagged organisms (herein referred to as acoustic telemetry). Most commonly, the tag produces a coded transmission at varying time intervals and if, at the time of transmission, the tag is within the detection range of a given receiver, the transmission is decoded and the ID, time, and date are logged on a storage device and sometimes relayed through a medium to an external portal. Acoustic telemetry systems offer a range of tags of different sizes and power outputs. Power output potential is strongly linked to tag size as it relates directly to transducer size and battery power, with larger batteries offering greater power delivery and longer tag life. As a result, larger tags are typically more powerful relative to smaller tags. A common approach in the field of acoustic telemetry is to issue the study animals with the largest and most powerful tag they can effectively carry without considerable energetic burden. This stems from the perception that more powerful tags are favorable as they can be detected by the receiver from the furthest distance; thus, the likelihood of detecting an animal is higher. However, since the detection range is a relationship between both the receiver and tag [4], the use of high-powered tags in certain study systems can lead to complexities in the detection range profiles that need to be considered.

Over the course of a study, there are numerous factors that can influence the relative performance of any acoustic telemetry system $[5,6]$. These factors include the physical and chemical properties of the water body, sea state/surface conditions, ambient noise, and physical obstruction $[4,7,8]$. Naturally, in all acoustic telemetry systems, the transmission is subject to several types of propagation loss as sound travels from the tag to the receiver [9]. These losses are caused by processes including spreading, reflection, scattering, absorption, and refraction [8]. A combination of the aforementioned factors and the specific power output of the acoustic tag employed define the detection range of the receivers. Additionally, in acoustic telemetry systems that operate on a single frequency, overlapping tag transmissions can inhibit the receiver's ability to decode them, despite both tags being within the detection range $[2,10]$. This event is called a tag collision and results in neither tag ID being recorded by the receiver despite the pings being received.

Understanding the dynamics of the detection range within a given study system has importance for both study design and data interpretation/analysis [2-4]. In recent years, more attention has been focused on receiver array performance during design and execution of acoustic telemetry studies. During detection range testing, some researchers have observed detection range profiles with an area of low receiver performance at near distance intervals (pers. comm.). This phenomenon has been coined as 'the doughnut effect' by many within the field of aquatic acoustic telemetry, however, it has not previously been defined or described in the literature. Most commonly, researchers are concerned with the maximum effective detection range of receivers, with no consideration given to the potential of a minimum effective detection range and the implications of its occurrence. When using a coded system working on a single frequency, under certain conditions, acoustic receivers can be subject to 'Close Proximity Detection Interference' (CPDI), which results in a detection range profile where detection proportions are low near and far from the receiver and peak somewhere in between. Here, the detection range test results, sourced from three telemetry based studies, are used to assess the phenomenon CPDI on the detection range profiles and the relationship of near receiver detection performance and tag power output, across contrasting aquatic environments. The potential implications are then assessed by examining hypothetical scenarios in which acoustic telemetry is commonly used and how study results could be potentially influenced.

Given the technical nature of this manuscript, it is recommended that the 'Methods' section is read prior to the results.

\section{Results}

\section{Effective detection ranges}

The detection range profiles varied among tag types in the Cumberland Sound detection range tests, but notably, a CPDI effect was observed for two of the high- 
powered tags (Figure 1). The largest CPDI effect was found for the V16-6H tag, with only $8.3 \%$ of transmissions detected at $55 \mathrm{~m}, 15.8 \%$ detected at $99 \mathrm{~m}$, and $27.7 \%$ detected at $221 \mathrm{~m}$. Detection proportions then increased to a maximum for the distance intervals tested with $88.8 \%$ detected at $370 \mathrm{~m}$ and consistently declined for all subsequent distance intervals tested. A CPDI effect was also observed for the $\mathrm{V} 13-2 \mathrm{H}$ tag detection range profile, with only $17.9 \%$ of transmissions detected at $55 \mathrm{~m}$ and $27.6 \%$ detected at $99 \mathrm{~m}$. After $99 \mathrm{~m}$, detection proportions increased to a maximum of $88.4 \%$ at $221 \mathrm{~m}$, followed by a consistent decline in transmission proportion detections with distance. No CPDI effect was present for the V9-1H tag detection range profile, with $89.8 \%$ of transmissions detected at $55 \mathrm{~m}$ and $99.7 \%$ at $99 \mathrm{~m}$.

When considering the V16-6H detection range profiles for all three contrasting study sites (Figure 2), it is apparent that a CPDI effect was present for high-powered tags in both the Arctic lagoon and temperate lake, but absent in the exposed sub-tropical coastal reef environment. The greatest CPDI effect of the three study sites occurred in the rocky sheltered Arctic embayment and was also notable in the temperate lake. In Jupiter, Florida, on the exposed sub-tropical reef, the greatest detection proportion was recorded at the closest distance from the receiver tested $(100 \mathrm{~m})$, indicating the absence of CPDI in this system.

When considering the influence of wind speed in the Arctic embayment, Cumberland Sound, it is apparent that wind speed has a negative relationship with CPDI. Setting an effective detection range of $60 \%$ detection proportion, profiles vary between tag types. For the V9 tag (Figure 3a), at 0 to $20 \mathrm{~m} / \mathrm{s}$, there was no minimum effective detection range, the maximum effective detection range was $330 \mathrm{~m}$, and a peak of $99.6 \%$ at the $99 \mathrm{~m}$ for the measured distance intervals. At $>20 \mathrm{~m} / \mathrm{s}$, there was again no minimum effective detection range, the maximum effective detection range was $300 \mathrm{~m}$, and a peak of $99.8 \%$ at the $99 \mathrm{~m}$ for the measured distance intervals. For the V13 tag (Figure 3b), at 0 to $20 \mathrm{~m} / \mathrm{s}$, the minimum effective detection range was $160 \mathrm{~m}$, the maximum effective detection range was $460 \mathrm{~m}$, and a peak of $87.7 \%$ at $370 \mathrm{~m}$ for the measured distance intervals. At $>20 \mathrm{~m} / \mathrm{s}$, the minimum effective detection range was $120 \mathrm{~m}$, the maximum effective detection range was $430 \mathrm{~m}$, and a peak of $95.3 \%$ at the $221 \mathrm{~m}$ for the measured distance intervals. For the V16 tag (Figure 3b), at 0 to $20 \mathrm{~m} / \mathrm{s}$, the minimum effective detection range was $300 \mathrm{~m}$, the maximum effective detection range was $540 \mathrm{~m}$, and a peak of $91.0 \%$ at the $370 \mathrm{~m}$ for the measured distance intervals. At $>20 \mathrm{~m} / \mathrm{s}$, the minimum effective detection range was $240 \mathrm{~m}$, the maximum effective detection range was $490 \mathrm{~m}$, and a peak of $85.1 \%$ at the $370 \mathrm{~m}$ for the measured distance intervals.

\section{System performance}

In the Lake Charlotte study, the number of pings received exceeded the number of pings transmitted $(n=67)$ up to a

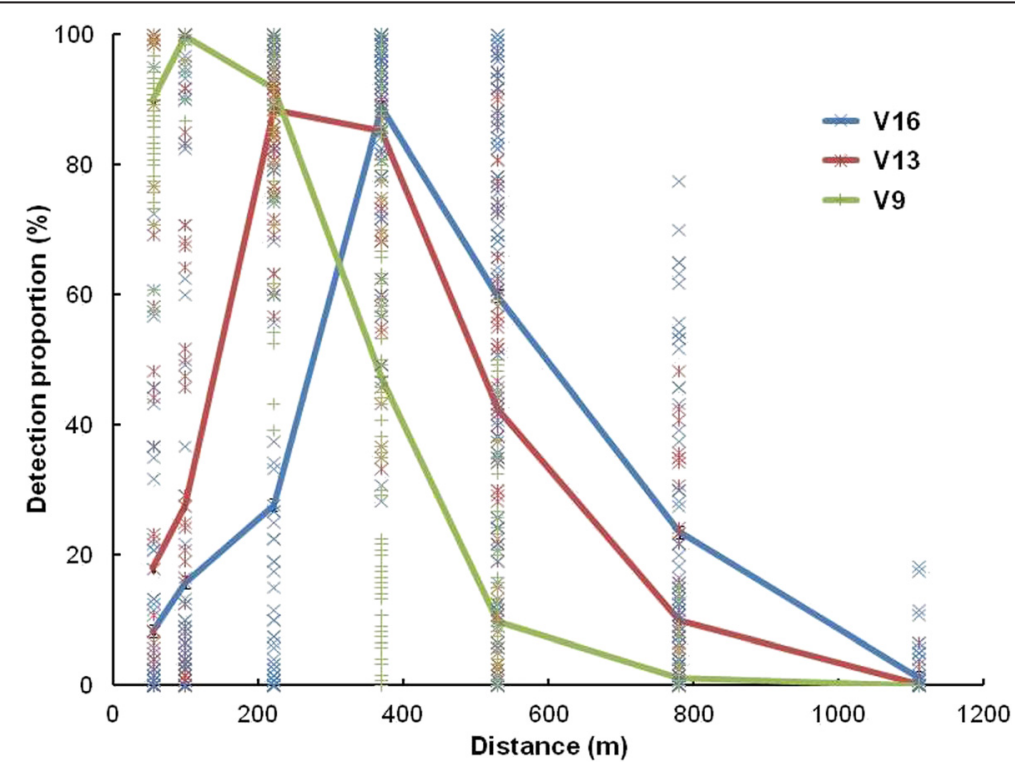

Figure 1 Detection proportion profiles for three tag types $(\mathrm{V} 16-6 \mathrm{H}, \mathrm{V} 13-2 \mathrm{H}$, and V9-1H) in the Cumberland Sound Arctic embayment. Solid lines denote mean detection proportions, while individual markers show hour proportion variability at each measured distance interval. The low power $\mathrm{V} 9$ tag showed no CPDI effect with 89.8\% detection proportion at $50 \mathrm{~m}$. The medium power V13 tag shows a clear CPDI effect, with the greatest proportion of detections (88.4\%) not occurring until $200 \mathrm{~m}$ distance from the receiver. The highest power V16 tag clearly shows the strongest CPDI effect, with the greatest proportion of detections (88.8\%) not occurring until $350 \mathrm{~m}$ distance from the receiver. 


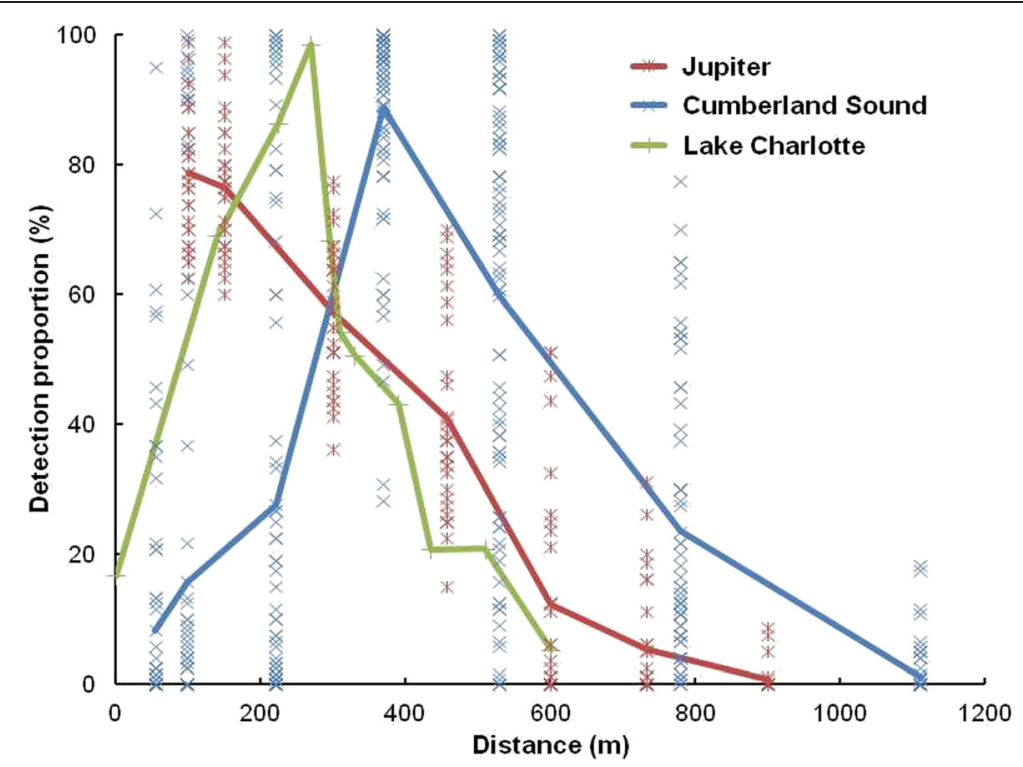

Figure 2 Detection proportion profiles for high-powered V16-6H tags in three contrasting study system: Jupiter, Florida (an exposed sub-tropical reef), Lake Charlotte, Nova Scotia (a freshwater temperate lake), and Cumberland Sound, Nunavut (a semi-enclosed Arctic embayment). Solid lines denote mean detection proportions, while individual markers show proportion variability at each measured distance interval for days (Jupiter) and hours (Cumberland Sound). No variability data is shown for Lake Charlotte, as only single values were collected at each distance interval. Plots show distinct CPDI effect to be present in both the Arctic embayment and freshwater lake, but absent at the exposed reef site, which showed a consistently declining profile from near to far.

distance of $180 \mathrm{~m}$ from the receiver, peaking at 186 pings recorded at a distance of $70 \mathrm{~m}$ (Figure 4). Therefore, at all distance intervals measured from $0 \mathrm{~m}$ to $180 \mathrm{~m}$, the received pings exceed $100 \%$ of the transmitted pings. The only possible explanation for the observed results is that, at these distances, the receiver was recording the reflected echoes of the produced pings.

\section{Functional example - gate}

When assuming no influence of CPDI, the $400-\mathrm{m}$ spacing provided effective detection coverage across the channel (Figure 5a, i). Transition distances within the effective detection range varied, depending on crossing point, between 698 and $800 \mathrm{~m}$ (Figure 5a, ii and iii). When a CPDI effect resulting in a minimum effective detection range of $200 \mathrm{~m}$ is considered, the gate would still provide full cross channel coverage; however, several areas along the gate would not provide effective coverage (Figure 5b, i). This would have a direct influence on the detection probability of a tagged individual crossing the receiver line, which would vary depending on the specific point of crossing. Transition distances within the effective detection range were lower overall and highly varied, depending on crossing point, between 366 and $732 \mathrm{~m}$ (Figure 5b, ii and iii).

\section{Functional example - positional array}

When assuming no influence of CPDI, the 400-m spacing would provide $100 \%$ coverage of the study site
(Figure 6a, i). Additionally, $44.3 \%$ of the bay would be covered by positional functionality (Figure 6a, ii), with three or more receivers providing the effective detection range for this area (Figure 6a, iii). When a CPDI effect resulting in a minimum effective detection range of $200 \mathrm{~m}$ is considered, the receiver spacing provides effective detection coverage for $91 \%$ of the bay, while the remaining $9 \%$ of the bay would remain outside of the effective detection range. Additionally, only $17 \%$ of the bay would be covered by positional functionality (Figure 6a, ii), with three receivers providing the detection range for this area (Figure 6a, iii).

\section{Discussion}

The data presented in this study demonstrate that in low ambient noise marine and freshwater environments, the detection range profiles of high-powered tags (V13-H and V16-H) can exhibit a CPDI effect. The extent of the CPDI effect appears to be primarily driven by tag power, with the higher power tags resulting in a greater effect. The detection range profiles were found to vary between periods of high and low wind speed, with the CPDI effect reduced during hours of high wind speed.

The occurrence of CPDI relates to the functionality of the tag receiver relationship. In shallow low ambient noise environments, hard surfaces, including the water surface when calm conditions persist, act as hard/clean sound barriers, resulting in strong and clean reflections of the transmitted pings [8]. When the receiver detects 

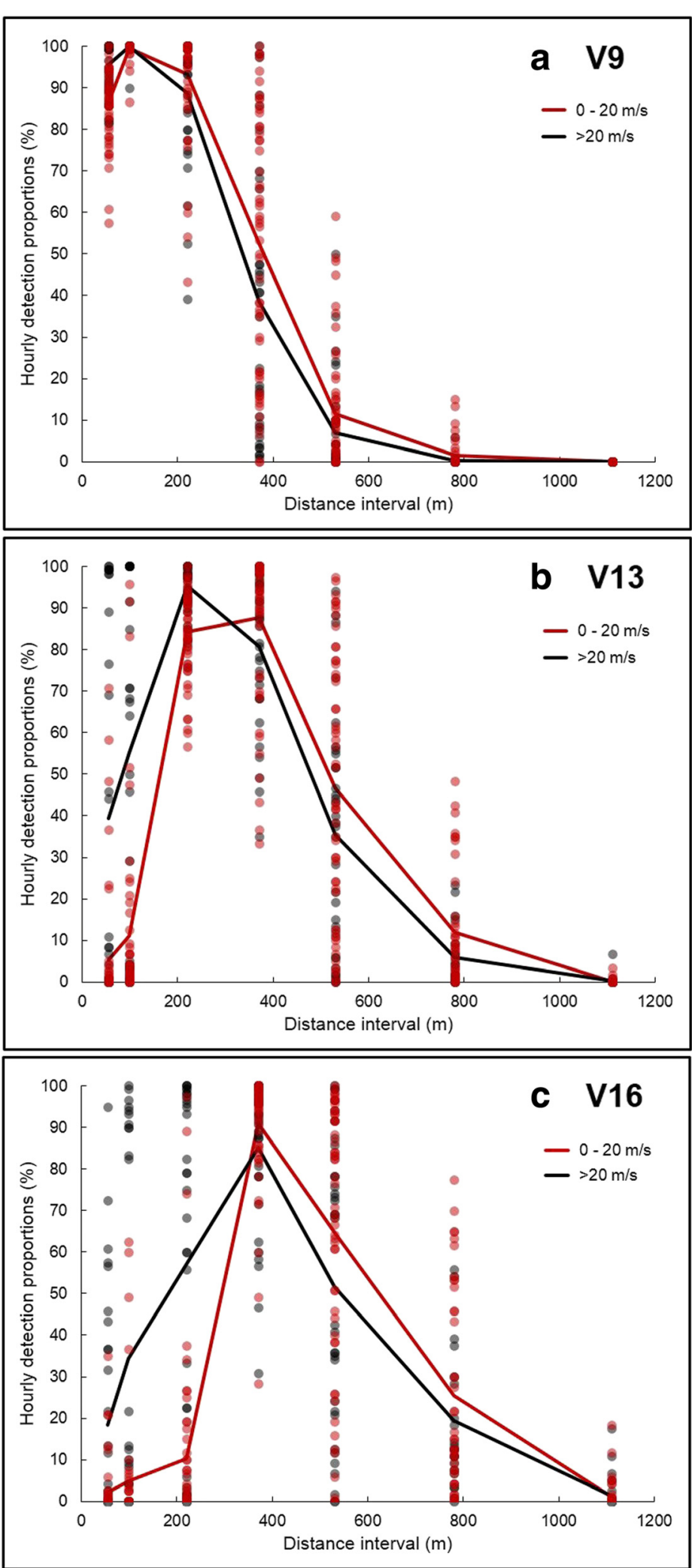

Figure 3 Detection range profiles during hours with low $(0$ to $20 \mathrm{~m} / \mathrm{s}$ red) and high ( $>20 \mathrm{~m} / \mathrm{s}$ black) wind speeds, at the Cumberland Sound study site Nunavut, Canada. Lines show mean detection proportions and dots show hourly proportions, displayed with 50\% transparency. (a) V9 transmitter. (b) V13 transmitter. (c) V16 transmitter. 


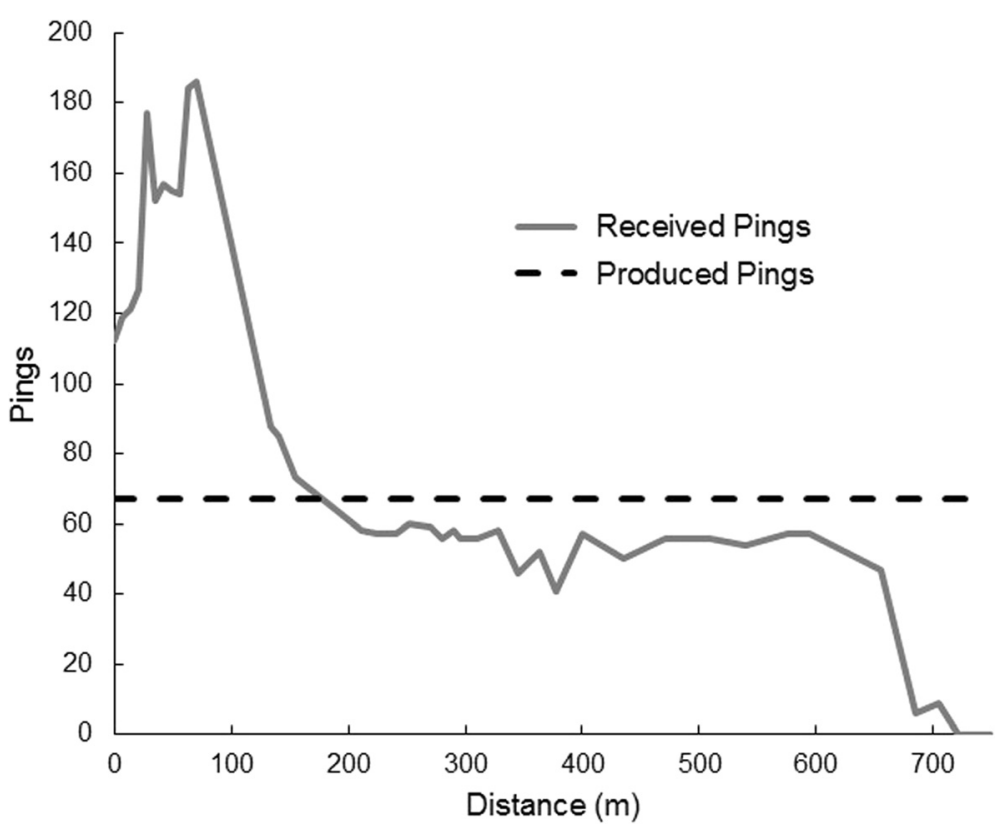

Figure 4 System performance of the received pings (solid gray line) relative to the transmitted pings (dashed black line) by distance interval from the acoustic receiver, at the Lake Charlotte study site, Nova Scotia, Canada. Between 0 and $180 \mathrm{~m}$ distance, the received pings exceed $100 \%$ of the transmitted pings, indicating a high incidence of echoes from the reflected pings.

the first ping of a transmission sequence, the blanking is initiated to avoid potential interference. Following this blanking period, the receiver listens for the second ping in the pattern of code pings. In these low ambient noise environments, the reflections of the strong signals from the high-powered tags are still clearly echoing in close enough proximity to the receiver to be redetected by the hydrophone and overlap with the subsequent pings. This phenomenon was evident in the system performance results of the Lake Charlotte detection range test, which showed that the reflected pings can greatly exceed the number of the transmitted pings. This restricts the ability of the receiver to differentiate between the true pings and the reflected pings. The original transmission is in essence colliding with itself, resulting in the transmission being discarded by the receiver as erroneous and the ID not being decoded or logged. Given the considerable level of the reflected pings observed in system performance test, these are almost certainly the predominant cause of CPDI.

During periods of high wind, the uniformity of the surface is disrupted, resulting in more scattering and weaker reflections/echoes. Additionally, the associated increase in ambient noise from the rough water surface and air entrainment from the wind-driven waves mutes any reflected sound waves [11], restricting or illuminating interference between the weaker echo and the stronger true signal in the code sequence. As such, the full code can be defined and the ID decoded and logged to memory. This was highlighted by the fact that wind speed showed a negative relationship with CPDI, since no CPDI was present for the V9 tag wind speed, as expected, only reduced the maximum detection range [11]. For the V13 and V16 tags, greater wind speed reduced both CPDI, thus the minimum effective detection range, and maximum effective detection range. Wind speed clearly had influence over CPDI at the Cumberland Sound study site; however, many factors that can affect the detection range profiles [4] were not tested and would certainly contribute to the profiles observed.

At the Jupiter study site, a combination of factors eliminated the occurrence of CPDI. Firstly, the site is more exposed, resulting in a consistently less uniform and therefore less reflective water surface. This exposure, coupled with high levels of anthropogenic activity, results in a higher level of ambient noise. Secondly, a large biomass of sub-tropical reef fauna is found on the nearby artificial reef, which is known to create sustained ambient noise [12]. Thirdly, the soft sand substrate would have absorbed sound waves reducing the strength of reflections relative to the hard rock in the Arctic embayment. Similar to the effects of wind, the combination of less reflective substrate and water surface and high levels of ambient noise reduced the potential for the weaker echoes to interfere with the stronger true code signals. As would be expected, these factors also resulted in a lower proportion of detections received at the distance of highest proportion detected $(78.7 \%$ at $100 \mathrm{~m})$, 


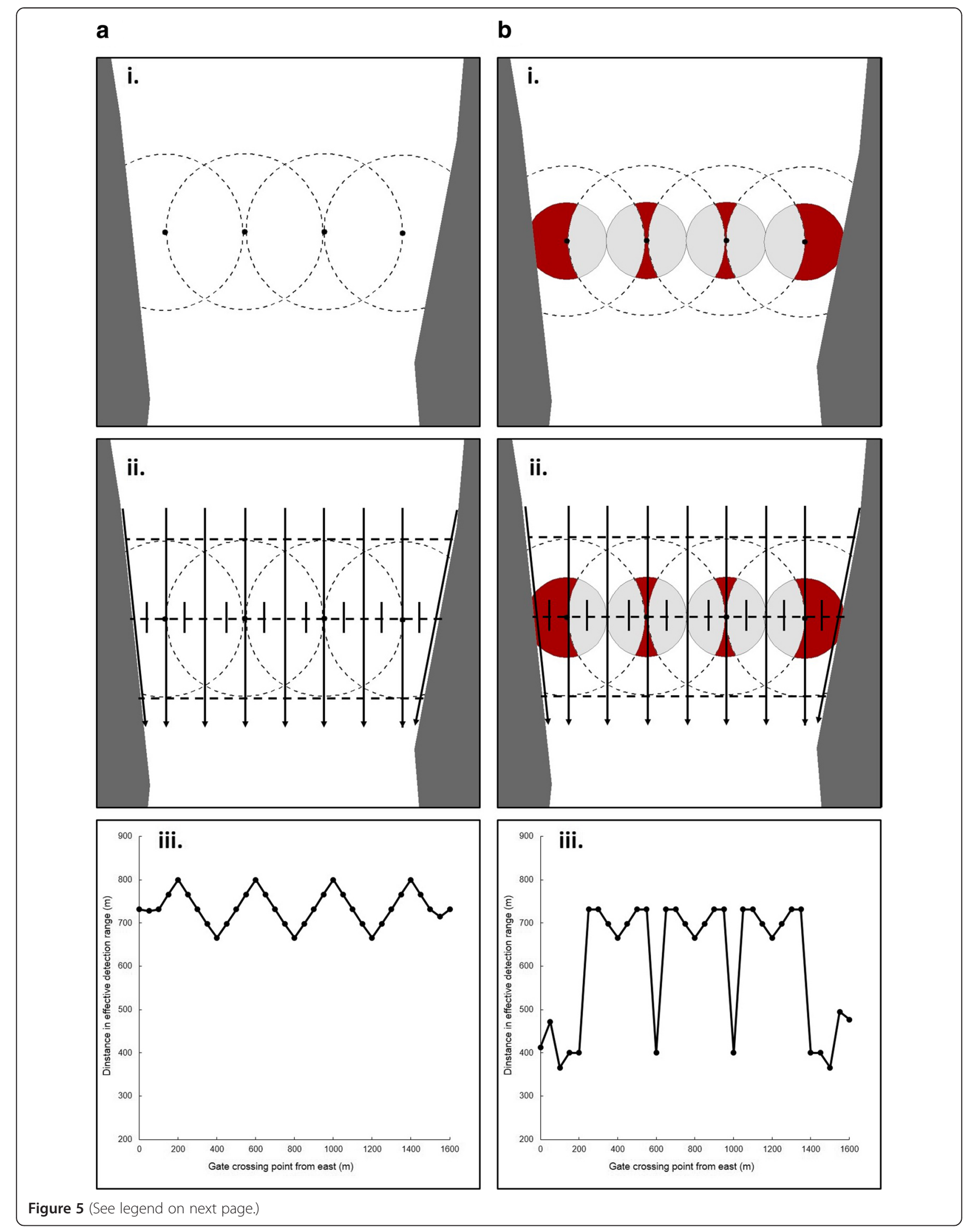

b 
(See figure on previous page.)

Figure 5 Functional acoustic gate/curtain example with (a) a 400-m maximum effective detection range and no CPDI effect considered and (b) a CPDI effect with a 200-m minimum effective detection range and a 400-m maximum effective detection range considered. In examples (a) and (b), i) shows the expected detection range, with gray areas showing the extent of minimum effective detection range, ii) shows the potential pathways the study animals could take as they cross the receiver gate, and iii) shows a plot of the distance (m) of transition across the gate within effective detection range at 50-m intervals from left to right (assuming a straight transition with no deviation).

as some transmissions were drowned out by high ambient noise. The absence of CPDI from the Jupiter study site detection range profile is consistent with the results of Cagua et al. [13]. They found, in a high ambient noise coral reef environment, the highest detection proportion occurred at $0 \mathrm{~m}$ distance, with progressively decreasing proportions thereafter, for both V16-H and V13-H tags.

The identification of CPDI has implications for future passive telemetry studies, as without its consideration, effective study design can be compromised. In studies investigating behavior and habitat use, particularly of less mobile and more sedentary benthic species, large areas of the study site could remain ineffectively monitored. A study animal could conceivably spend a large proportion of time in close proximity to a given receiver with a low probability of detection. This could lead to data misinterpretation, particularly in relation to site fidelity, home range calculations, and habitat use. For example, if a study animal in an array design, that was subject to a large CPDI effect, were to remain in close proximity to a given receiver, an adjacent receiver could record a far greater number of detections. The data would erroneously suggest that the animal was spending the majority of its time in close proximity to the adjacent receiver and then moving to the near receiver in response to high wind conditions. In reality, the animal would have remained sedentary in close proximity to the near receiver the whole time. This example may be an oversimplification given that the detection range tests presented in this study are derived from static transmitters in a relatively linear directional plane. Movement around a receiver by a tagged animal may result in varying proportions of the effective detection range, which would be further complicated by changes in depth, topography, and other physical obstructions. It is highly unlikely for a detection range profile in one linear plane to be uniform around an entire receiver site (for example, see [14]). Thus, the detection range tests along multiple axes from receiver sites are recommended to gain a comprehensive understanding of array performance [4]. Regardless, without consideration, detections from an array that is experiencing CPDI could be misinterpreted from a spatial use perspective.

For studies employing gates/curtains to document migration timing and survival rates, areas of low detection probability could be encountered as the study animals cross the receiver lines (Figure 5). The animal would pass through an area of the effective detection range as it approached and departed the line, but the effective range encountered on approach, transition, and departure would vary relative to the specific path taken. Thus, the proportion of time, based on swimming speed, spent within the effective detection range of the gate as the animal crosses it would be underestimated. The full probability of detecting the animal will be a function of the detection probability in the zones as it crosses through the gate along with the transmission periodicity of the tag, the swimming speed of the animal, and the probability of ping collision. Underestimation of detection probability would lead to inaccurate detection efficiency predictions/calculations, in turn, the potential for misinterpretation of detection results. For positional grid systems, it is necessary for the study animal to be within the effective detection range of at least three receivers for a position to be triangulated $[7,15]$. Not considering the potential presence of CPDI could lead to ineffective tag choices and grid spacing, resulting in issues with or even an inability to reconstruct locations in post processing (Figure 6).

The existence of CPDI could also have implications for the effective operation of business card tags. Business card tags are small receivers attached to study animal intended to assess the level of associations (for example, schooling, predator-prey events) between tagged individuals [16]. If an effect of CPDI was present, it could greatly reduce the ability of the business card tag to detect other tagged individuals associating with them in close proximity. To date, the presence of CPDI has not been reported for this technology.

\section{Conclusions}

The identification of CPDI highlights the need for consideration of its implications, in both array/receiver placement design and tag selection. Researchers employing acoustic telemetry should not only consider and account for the maximum effective detection range of their receivers but, also it is equally important to consider and account for the potential of CPDI. This can be achieved by standard detection range tests undertaken during the study [4]. As these data show, it is probable that CPDI only occurs under certain conditions. For example, it is unlikely to exist in typically high energy/ambient noise systems. However, for study systems that are subject to low ambient noise levels and hard substrates, 

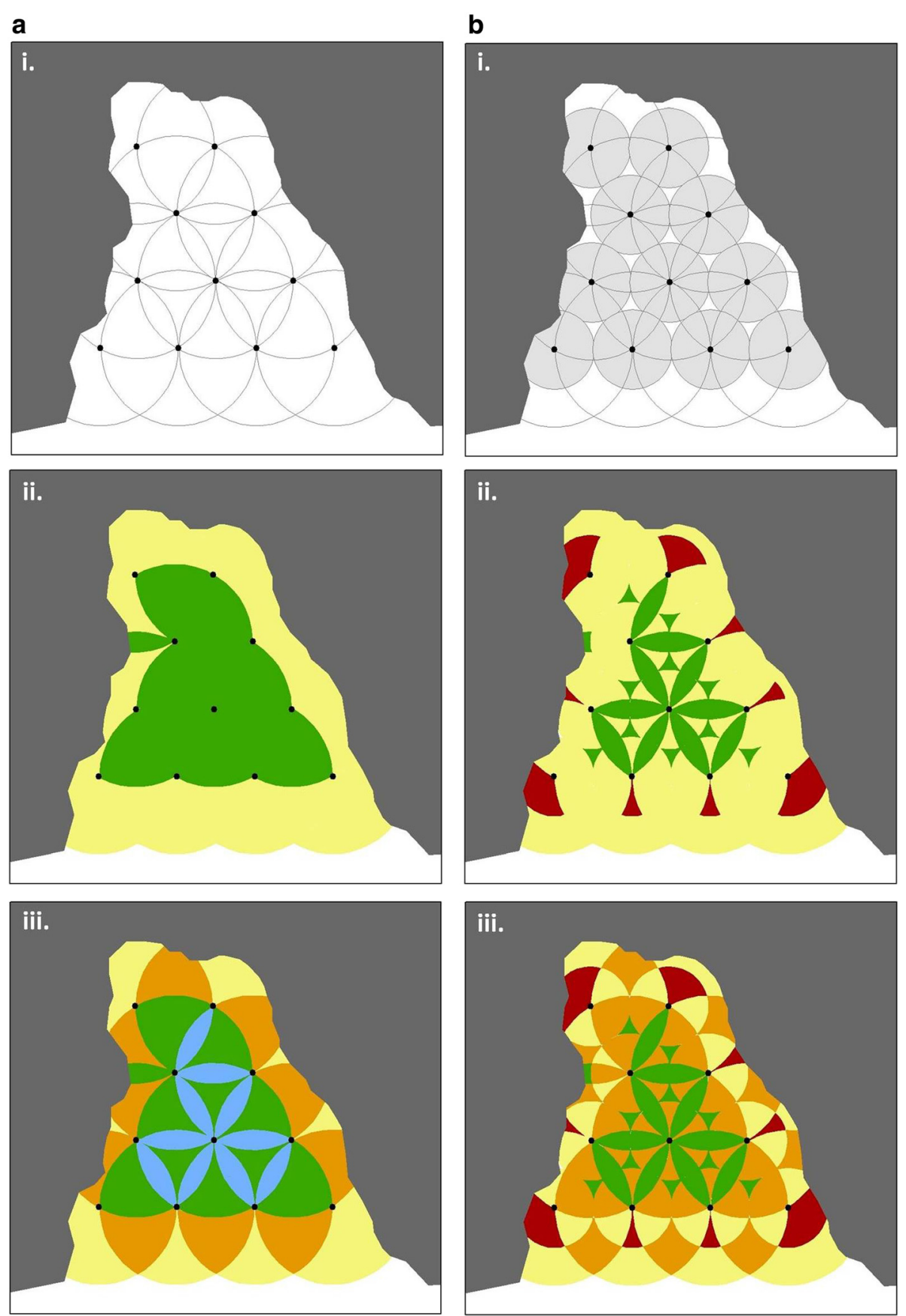

Figure 6 Functional positional array example with (a) a 400-m maximum effective detection range and no CPDI effect considered and (b) a CPDI effect with a 200-m minimum effective detection range and a 400-m maximum effective detection range considered. In example (a) and (b), i) shows the expected detection range, with gray areas showing the extent of minimum effective detection range, ii) shows the effective acoustic coverage in yellow, effective positional coverage in green and acoustic coverage dead zones in red, iii) shows the number of receivers giving effective acoustic coverage across the bay, with red showing zero, yellow showing one, orange showing two, green showing three, and blue showing four receivers.

tag type and power output choice should reflect the relative potential of sound reflection within that water body. The phenomenon of CPDI, and its significant relationship to environmental conditions, again highlights the importance of continual detection range monitoring over the course of a study [4]. Only with a comprehensive understanding of temporal detection range profiles is it possible to accurately interpret the detection data. 


\section{Methods}

\section{Acoustic telemetry system}

Many acoustic telemetry systems operate on a single frequency and rely on coded transmissions to uniquely identify tags. For this study, the Vemco ${ }^{\oplus}$ VR2W $69 \mathrm{kHz}$ coded signal system (Vemco Ltd., Bedford, Nova Scotia, Canada) was used. This telemetry system functions by acoustic tags sending out a series of signals or 'pings' (8 to 10 ) over a short period (3.5 to $5 \mathrm{~s}$ ) at random intervals. A receiver must then detect an entire ping series correctly to calculate the ID code, which is recorded along with date and time. To minimize the potential of additional noise sources interfering with the transmission sequence, following the reception of each ping in the sequence, the receiver initiates a blanking period of $260 \mathrm{~ms}$ to avoid accepting reverberations and echoes as a valid ping.

\section{Detection range tests}

As components of acoustic telemetry based studies, three detection range tests were conducted in contrasting water bodies: a marine Arctic embayment, a freshwater temperate lake, and a marine sub-tropical coastal reef line. These study sites provided variable environments to assess the detection range profiles for the occurrence and extent of CPDI. It must be noted that it is possible that variations between the experimental designs may have limited the potential for direct comparison between study sites. For the purposes of this study, it is assumed that study design would influence the detection potential equally across all distance intervals and, therefore, not be the cause of the general detection range profiles observed.

\section{Cumberland Sound, Baffin Island, Nunavut, Canada $\left(66^{\circ} 01^{\prime} \mathrm{N}, 66^{\circ} 04^{\prime} \mathrm{W}\right)$}

A semi-enclosed marine Arctic embayment, on the edge of Cumberland Sound, was subject to minimal anthropogenic activity (Figure 7). The site is characterized by a high shoreline, offering shelter from light winds, with a relatively uniform hard rock substrate. The detection range test consisted of an acoustic tag mooring with V16-6H (158 dB), V13-2H (153 dB), and V9-1H (151 dB; $\mathrm{Vemco}^{\circ}$ ) tags attached (Figure $8 \mathrm{~A}$ ), set in approximately $30 \mathrm{~m}$ water depth. The moorings for both tags and receivers consisted of an approximately $50 \mathrm{~kg}$ meshwrapped rock anchors and a 10-m-long 20-mm diameter rope riser attached to a rigid surface float. Acoustic tags were attached to the mooring rope on an approximately $3 \mathrm{~cm}$ stalk of stainless steel wire, approximately $5 \mathrm{~m}$ above the seabed. Eight VR2W $69 \mathrm{kHz}$ acoustic receivers were set at increasing distance intervals from the tag mooring: 55, 99, 221, 370, 530, 780, and $1,110 \mathrm{~m}$, providing eight detection range distance validations for all three tag types (Figure 8A). The receiver moorings were the same design as the acoustic tag mooring, with the receivers attached $5 \mathrm{~m}$ above the substrate. Each tag was programmed to transmit at a fixed interval every $28 \mathrm{~s}$, and tags were activated in sequence approximately $9 \mathrm{~s}$ apart to prevent transmission overlap and therefore potential tag collision. The detection range test was conducted over 5 days from 14 to 18 July 2011. Weather conditions were calm until the morning of the 17 July when there was a storm. During this time, the 780-m distance receiver was displaced from the detection range test setup. As such, all results from this distance interval after this time were not considered for analysis.

\section{Lake Charlotte, Nova Scotia, Canada $\left(44^{\circ} 51^{\prime} \mathrm{N}, 63^{\circ} 11^{\prime} \mathrm{W}\right)$}

Lake Charlotte is a freshwater temperate lake subject to minimal anthropogenic activity (Figure 7). The site is surrounded by trees providing shelter from light winds, with a bottom depth of approximately $40 \mathrm{~m}$. The substrate was relatively uniform and consisted of soft mud. The detection range test involved a fixed VR2W $69 \mathrm{kHz}$ acoustic receiver mooring, which consisted of a $20-\mathrm{kg}$ base weight and a $5-\mathrm{m}$-long $20-\mathrm{mm}$ rope riser attached to a rigid surface float (Figure $8 \mathrm{~b}$ ). The acoustic receiver was attached to the rope approximately $3 \mathrm{~m}$ above the substrate. A V16-6H (158 dB) acoustic tag was attached to a sink line that was lowered over the side of a vessel to a depth of 2.5 to $3 \mathrm{~m}$. The tag was programmed to transmit on a fixed interval of $7 \mathrm{~s}$. The vessel was moved progressively further away from the receiver and held in position at 11 distance intervals for $180 \mathrm{~s}$ at each. This provided detection range validations for $0,140,225,270$, 295, 310, 330, 390, 435, 510, and $600 \mathrm{~m}$ (Figure 8b). In order to test the performance of the acoustic telemetry system, the detection range test was repeated with 60-s intervals, with the receiver recording raw pings rather than decoded detections. The detection range test durations were $2 \mathrm{~h}$ each and were carried out on 1 and 2 September 2007, during which time weather conditions were calm (wind < $10 \mathrm{kts}$ ).

\section{Jupiter, Florida, USA $\left(26^{\circ} 58^{\prime} \mathrm{N}, 80^{\circ} 01^{\prime} \mathrm{W}\right)$}

Jupiter, Florida, USA, is an exposed sub-tropical marine reef line approximately 3 miles offshore of Jupiter Inlet, subject to a high level of anthropogenic activity predominantly through boating, fishing and scuba diving (Figure 7). The site is located on the edge of the Gulf Stream, thus, it is subject to consistent currents, exposed to weather conditions, and has a bottom depth of approximately $20 \mathrm{~m}$. The substrate is relatively uniform consisting of approximately $1.5 \mathrm{~m}$ of sand overlaid on hard reef. The detection range test site was in close proximity to an artificial reef in the form of a sunken barge, which was rich in marine life. The detection range test consisted of three V16-6H tag 


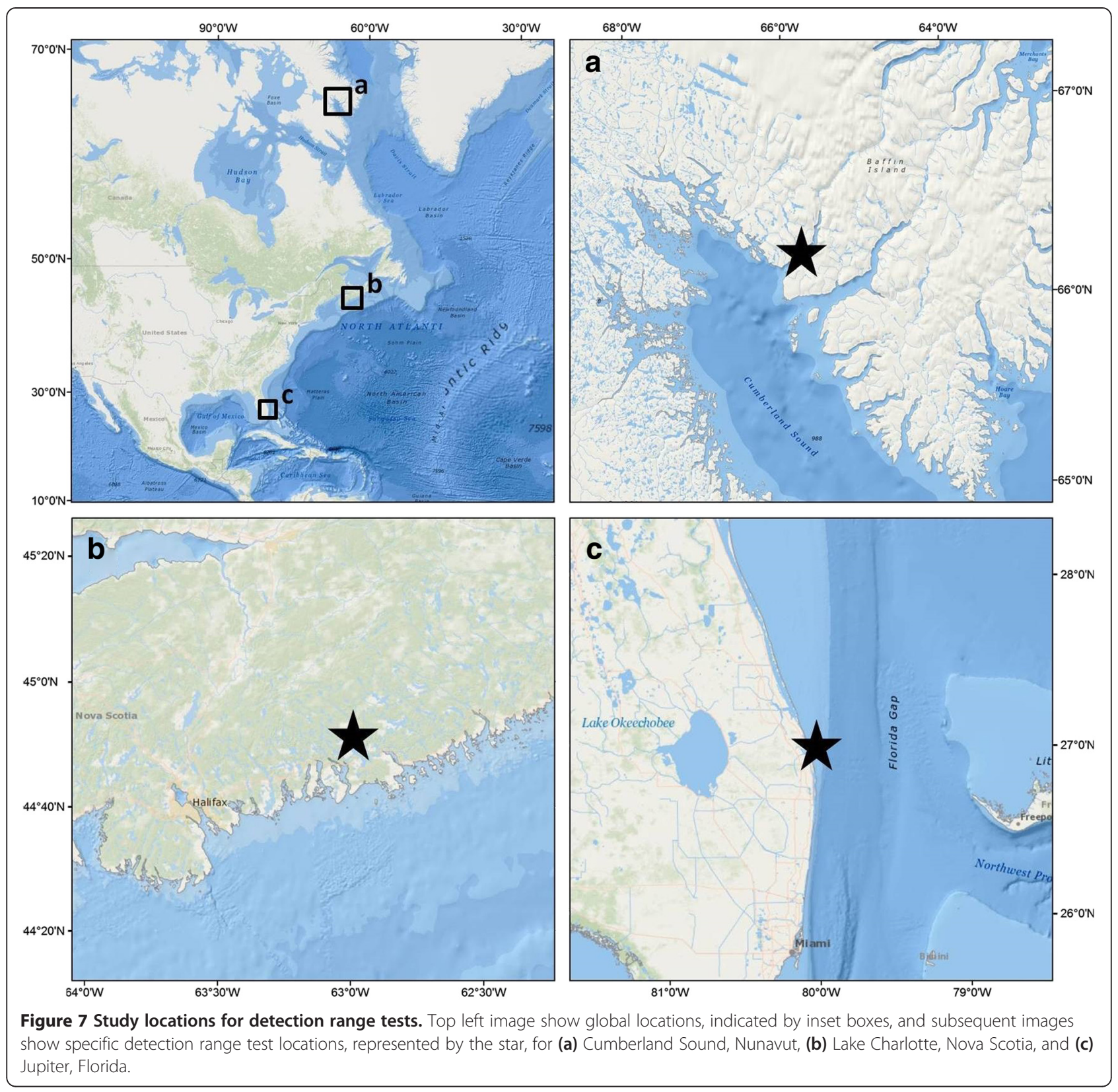

moorings and three VR2W $69 \mathrm{kHz}$ receiver moorings (Figure 8c). Receiver moorings consisted of a 1.5-m auger anchor screwed into the sand up to the eye and $3 \mathrm{~m}$ of $1 /$ 4" braided stainless steel aircraft cable riser attached to a rigid subsurface float. The acoustic receivers were attached to the riser $2 \mathrm{~m}$ above the substrate. The acoustic tag moorings consisted of a 1-m auger anchor screwed into the sand up to the eye. Attached to this was a rigid 1$\mathrm{m}$ stainless steel riser with the acoustic tag affixed on top. The three receivers were positioned 300 and $200 \mathrm{~m}$ apart; thus, it was possible to test six linear distance parameters: 100, 150, 300, 458, 600, 733, and $900 \mathrm{~m}$ (Figure 8c). The tags were programmed to transmit on a fixed interval once every $900 \mathrm{~s}$. The detection range test duration was 1 month from 14 July to 13 August 2009.

\section{Analysis}

For each tag at each distance interval, the proportion of expected transmissions, based on the nominal delay and accounting for transmission duration, detected during a set time period (see below) was calculated. For the Cumberland Sound, the detection range tests proportions at each distance interval were calculated during each hour and for Lake Charlotte for each 2-min interval. For Jupiter, the detection range tests mean proportions were assessed by day due to the lower 


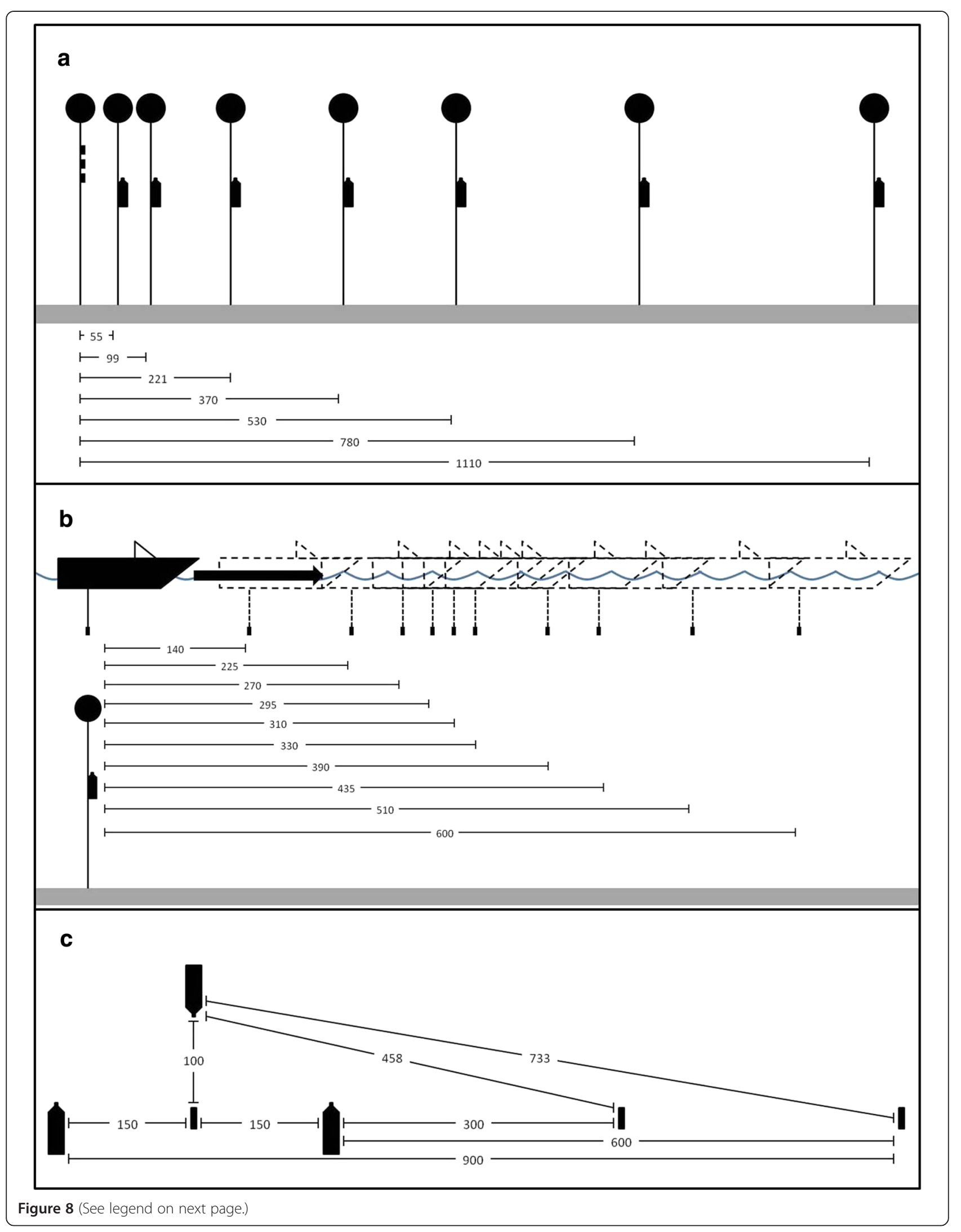


(See figure on previous page.)

Figure 8 Study design for conducted range tests. (a) Cumberland Sound, Nunavut, Canada - fixed transmitter mooring to far left, consisting of three transmitter types $(\mathrm{V} 16, \mathrm{~V} 13$, and V9), with fixed receiver moorings at increasing distance intervals. Depth from surface to substrate is approximately 30 m. (b) Lake Charlotte, Nova Scotia, Canada - fixed receiver mooring to the left. Vessel with test V16 transmitter lowered over the side of the vessel to a depth of 2.5 to $3 \mathrm{~m}$. The vessel was moved to set distances from the receiver mooring and held at increasing distance intervals for $180 \mathrm{~s}$ at each. Depth from surface to substrate is approximately $40 \mathrm{~m}$. (c) Jupiter, Florida, USA - as if viewed from directly above - three fixed receiver mooring to the left and three fixed V16 transmitter moorings providing seven distance intervals. Depth from surface to substrate is approximately $20 \mathrm{~m}$. Diagrams are not to scale.

transmission rate. To assess the influence of wind speed on CPDI, for the Cumberland Sound detection range test, the data was divided into hours with wind speeds up to $20 \mathrm{~m} / \mathrm{s}$ and hours with wind speeds $>20 \mathrm{~m} / \mathrm{s}$. For each tag type (V9, V13, and V16), both detection proportion profiles were plotted on the same chart for comparison. Weather data was obtained from the Environment Canada Pangirtung weather station online records (climate.weather.gc.ca). To test the system performance for the mechanism driving CPDI, raw ping files were analyzed from the Lake Charlotte range test. It was only possible to assess the raw file from the Lake Charlotte detection range tests, as this was the only location where only a single tag and single receiver was used. This meant that the exact number of produced pings at each distance interval could be calculated and plotted for comparison against the number of pings received.

\section{Functional examples}

To explore the potential implications of CPDI, its influence on two hypothetical study scenarios was investigated, one employing an acoustic gate ${ }^{\mathrm{a}}$ (Figure 5) and the other using a positional array grid to study movements in an embayment (Figure 6). Acoustic gates are typically employed to assess the timing of movements/ migrations through streams, river, estuaries, and coastal waters (for example, $[17,18]$ ), while positional array grid systems are commonly employed to assess fine-scale habitat use (for example, $[19,20]$ ). Both array designs rely on good receiver performance and overlapping ranges for effective functioning, gates to ensure high detection probability as a specimen crosses from one side to the other, and positional array grid systems require a transmission to be detected by at least three receivers to calculate a position.

A CPDI resulting in a minimum effective detection range of $200 \mathrm{~m}$ and a maximum effective detection range of $400 \mathrm{~m}$ was adopted for both scenarios. The hypothetical effective detection ranges were defined from possible distances for $50 \%$ detection probability [4], feasible values based on the results of this study (see below). The distance between receivers was set to $400 \mathrm{~m}$ for both scenarios. Monitor positions were plotted in ArcMap $10^{\circ}$, and the detection ranges were depicted using the distance buffer tool. For both examples, the presence of a CPDI effect and no effect on the detection range profiles were investigated. To explore the impact of CPDI on detection probability of the gate system, the distance a tagged individual would experience effective detection range during a transition, assuming a straight path was taken, was measured at 50-m intervals along the gate from left to right. This was plotted against position along the gate to demonstrate the variability that would be experienced in each scenario. For each path, the proportion of the transition across the line spent in and out of the effective detection range (that is, between 200 and $400 \mathrm{~m}$ distance from any given receiver) was calculated.

To explore the impact of CPDI on the functionality of the positional array grid system, no receiver coverage, single receiver coverage, and overlapping detection range areas were isolated and converted into polygon groups based on the number of receivers with the effective detection range within each given area. The area covered by each polygon group was calculated to provide the proportion of the study area covered by the effective detection range and the proportion with effective positional functionality (that is, covered by the detection range of at least three receivers) both with and without CPDI. Assumptions for both functional examples were as follows: the detection range profiles were consistent between all receiver sites, completely uniform around all receiver sites, and uniform over time (that is, not influenced by external variables), and tag collisions would not influence detection probability.

\section{Endnotes}

${ }^{\mathrm{a}}$ Also referred to as curtains.

\section{Abbreviation}

CPDI: Close proximity detection interference.

\section{Competing interests}

The authors declare that they have no competing interests.

\section{Authors' contributions}

SK conceived, conducted, and analyzed the Jupiter, Florida, portion of the study, participated in the analysis of the Arctic data, and drafted the manuscript. NH and AF conceived, conducted, and analyzed the Arctic portion of this study and assisted with the drafting of the manuscript. DW and MS conceived, conducted, and analyzed the Lake Charlotte portion of this study and assisted with the drafting of the manuscript. SG oversaw and participated in the data collection for the Jupiter, Florida, portion of this study. JY assisted with the design and data collection for the Jupiter, Florida, portion of this study. All authors read and approved the final manuscript. 


\section{Acknowledgements}

Support for this project was provided by funding from the Natural Sciences and Engineering Research Council of Canada (NSERC) and Canada Foundation for Innovation (International Joint Ventures Fund) through the Ocean Tracking Network, by the Swiss Shark Foundation - Hai Stiftung and the Bimini Biological Field Station Foundation. Permissions are from the Department of Fisheries and Oceans, Pangnirtung Hunters and Trappers Association, Government of Nunanvut, Florida Fish and Wildlife and National Marine Fisheries Service. The authors acknowledge the field support from Peter Kilabuk, Devin Imrie, Kendra Ulrich, Bil Parks, Cheryl Carroll, Walt Stearns, Mike Newman, and all Jupiter lemons shark project staff and volunteers. Content consultation from Victoria Piñheiro, Jeanette Bearding and Denise King is acknowledged. We would finally like to thank the editor and three anonymous reviewers for their thorough and highly constructive comments on the earlier draft of this manuscript, which improved the current version.

\section{Author details}

${ }^{1}$ Great Lakes Institute for Environmental Research, University of Windsor, 401 Sunset Ave, Windsor, ON N9B 3P4, Canada. ${ }^{2}$ Vemco Ltd., 20 Angus Morton Drive, Bedford, NS B4B OL9, Canada. ${ }^{3}$ Bimini Biological Field Station, South Bimini, Bahamas. ${ }^{4}$ Florida Fish and Wildlife Conservation Commission, Tequesta Field Laboratory, Fish and Wildlife Research Institute, 19100 Southeast Federal Hwy, Tequesta, FL 33469, USA. ${ }^{5}$ Port Elizabeth Museum at Bayworld, PO Box 13147, Humewood 6013, South Africa. ${ }^{6}$ Department of Zoology, Nelson Mandela Metropolitan University, PO Box 77000, Port Elizabeth 6031, South Africa.

\section{Received: 4 November 2014 Accepted: 6 February 2015}

Published online: 28 March 2015

\section{References}

1. Heupel MR, Webber DM. Trends in acoustic tracking: where are the fish going and how will we follow them? Am Fish Soc Symp. 2012;76:219-31.

2. Heupel MR, Semmens JM, Hobday AJ. Automated acoustic tracking of aquatic animals: scales, design and deployment of listening station arrays. Mar Freshw Res. 2006;57:1-13.

3. Payne N, Gillanders B, Webber D, Semmens J. Interpreting diel activity patterns from acoustic telemetry: the need for controls. Mar Ecol Prog Ser. 2010;419:295-301.

4. Kessel ST, Cooke SJ, Heupel MR, Hussey NE, Simpfendorfer CA, Vagle S, et al. A review of detection range testing in aquatic passive acoustic telemetry studies. Rev Fish Biol Fish. 2014;24:199-218.

5. Singh L, Downey NJ, Roberts MJ, Webber DM, Smale MJ, van den Berg MA, et al. Design and calibration of an acoustic telemetry system subject to upwelling events. Afr J Mar Sci. 2009;31:355-64.

6. How JR, de Lestang S. Acoustic tracking: issues affecting design, analysis and interpretation of data from movement studies. Mar Freshw Res. 2012;63:312-24.

7. Simpfendorfer CA, Heupel MR, Hueter RE. Estimation of short-term centers of activity from an array of omnidirectional hydrophones and its use in studying animal movements. Can J Fish Aquat Sci. 2002;59:23-32.

8. Medwin H, Clay CS. Fundamentals of Acoustical Oceanography. San Diego: Elsevier Science; 1997.

9. Haines G. Sound underwater. Newton Abbot: David and Charles; 1974

10. Melnychuk MC. Detection efficiency in telemetry studies: definitions and evaluation methods. Telemetry techniques: American Fisheries Society; 2012.

11. Gjelland $K \varnothing$, Hedger RD. Environmental influence on transmitter detection probability in biotelemetry: developing a general model of acoustic transmission. Methods Ecol Evol. 2013;4:665-74.

12. Radford CA, Stanley JA, Tindle CT, Montgomery JC, Jeffs AG. Localised coastal habitats have distinct underwater sound signatures. Mar Ecol Prog Ser. 2010;401:21-9.

13. Cagua EF, Berumen ML, Tyler EHM. Topography and biological noise determine acoustic detectability on coral reefs. Coral Reefs. 2013;32:1123-34.

14. Sakabe R, Lyle JM. The influence of tidal cycles and freshwater inflow on the distribution and movement of an estuarine resident fish Acanthopagrus butcheri. J Fish Biol. 2010;77:643-60.

15. Espinoza M, Farrugia TJ, Webber DM, Smith F, Lowe CG. Testing a new acoustic telemetry technique to quantify long-term, fine-scale movements of aquatic animals. Fish Res. 2011;108:364-71.
16. Holland KN, Meyer CG, Dagorn LC. Inter-animal telemetry: results from first deployment of acoustic 'business card' tags. Endanger Species Res. 2009;10:287-93.

17. Thorstad EB, Uglem I, Finstad B, Kroglund F, Einarsdottir IE, Kristensen T, et al. Reduced marine survival of hatchery-reared Atlantic salmon postsmolts exposed to aluminium and moderate acidification in freshwater. Estuar Coast Shelf Sci. 2013;124:34-43.

18. Melnychuk MC, Christensen V, Walters CJ. Meso-scale movement and mortality patterns of juvenile coho salmon and steelhead trout migrating through a coastal fjord. Environ Biol Fish. 2013;96:325-39.

19. Espinoza M, Farrugia TJ, Lowe CG. Habitat use, movements and site fidelity of the gray smooth-hound shark (Mustelus californicus Gill 1863) in a newly restored southern California estuary. J Exp Mar Biol Ecol. 2011;401:63-74.

20. Dean MJ, Hoffman WS, Zemeckis DR, Armstrong MP. Fine-scale diel and gender-based patterns in behaviour of Atlantic cod (Gadus morhua) on a spawning ground in the Western Gulf of Maine. ICES J Mar Sci: J Conseil. 2014;71:1474-89

\section{Submit your next manuscript to BioMed Central and take full advantage of:}

- Convenient online submission

- Thorough peer review

- No space constraints or color figure charges

- Immediate publication on acceptance

- Inclusion in PubMed, CAS, Scopus and Google Scholar

- Research which is freely available for redistribution 